\title{
Histopathological and biochemical assessment of the therapeutic effect of gold nanoparticles on experimental chronic toxoplasmosis \\ Original
}

Article
Manal R GabAllah ${ }^{1}$, Ashraf MA Barakat ${ }^{2}$, Noha S Ahmed ${ }^{1}$, Nada A El-Nadi ${ }^{1}$

Medical Parasitology Department, Faculty of Medicine, Sohag University, Sohag', and Zoonotic Diseases Department, National Research Centre, Giza², Egypt

\begin{abstract}
Background: Toxoplasmosis is a zoonotic disease caused by the intracellular opportunistic protozoan, T. gondii that infects both vertebrate and invertebrate cells. Nanoparticles (NPs) provide promising therapeutic agents for effective treatment of parasitic diseases, by overcoming the drawbacks of low bioavailability and poor cellular permeability of anti-parasitic drugs.

Objective: To assess the therapeutic effect of gold (Au) NPs on experimentally infected mice with chronic toxoplasmosis.

Material and Methods: Sixty-five laboratory-bred female Swiss albino mice were included. Five mice were left as control negative (non-infected non-treated), while the rest were experimentally infected orally with avirulent T. gondii strain (ME49). Fifty days post infection (pi), infected mice were divided into 4 groups (15 mice each); group 1: control group (infected non-treated); group 2: treated with Spiramycin (Rovamycin); group 3: treated with low-dose AuNPs; and group 4: treated with high-dose AuNPs. Treatment was administered orally for 10 days. All mice were sacrificed sixty days pi. Assessment of the therapeutic effect of AuNPs was achieved using parasitological, histopathological and biochemical parameters. The first included estimation of the parasite tissue cysts numbers and size in impression smears from brain, liver and spleen; histopathological parameters evaluated inflammation, necrosis and hemorrhages in tissues. Liver transaminases: aspartate transaminase (AST) and alanine transaminase (ALT) were measured in sera of all groups as a biochemical parameter.

Results: Statistically significant reductions were observed in the mean cyst count and size in brain, liver, and spleen of the infected treated group with high dose AuNPs (group 4) compared to the other infected groups. Histopathological examination of the brain, liver and spleen tissues showed that inflammatory reaction was decreased in both AuNPs-treated groups in comparison to Spiramycin-treated group and the non-treated mice. There was a significant reduction in the mean values of ALT and AST in mice treated with AuNPs high dose in comparison to other groups $(P<0.05)$.
\end{abstract}

Conclusion: AuNPs have a potentially therapeutic effect especially the high dose against experimental chronic toxoplasmosis.

Keywords: avirulent ME49 strain, chronic toxoplasmosis, experimental study, gold nanoparticles, Spiramycin.

Received: 20 April, 2021, Accepted: 25 July, 2021.

Corresponding Author: Noha S. Ahmed, Tel.: +20 1273126001, E-mail: nohasammer@yahoo.com

Print ISSN: 1687-7942, Online ISSN: 2090-2646, Vol. 14, No. 2, August, 2021.

\section{INTRODUCTION}

Toxoplasmosis is a disease caused by the protozoan parasite $T$. gondii, which is an obligatory intracellular coccidian parasite belonging to the Apicomplexa phylum ${ }^{[1]}$. Humans, other mammals, and birds are intermediate hosts, while cats are the definitive hosts ${ }^{[2]}$. Humans may become infected by eating undercooked meat that contains tissue cysts, or from contamination with sporulated oocysts from soil[ ${ }^{[3]}$.

In immunocompetent patients, the acute acquired infection is normally benign, with self-limiting adenopathy. In healthy individuals, the chronic latent infection is asymptomatic and is associated with tissuelocalized cysts, often in the brain and muscle tissues ${ }^{[4]}$.
Reactivation of tissue cysts in a healthy individual is usually asymptomatic, but immunocompromised individuals are at risk of developing life- threatening disease ${ }^{[5]}$.

The diagnosis of acute infection is established by the presence of tachyzoites in tissue parts and/or smears of body fluid (CSF, amniotic, or bronchoalveolar lavage fluids ${ }^{[6]}$. The presence of several tissue cysts indicates the presence of a chronic infection ${ }^{[7]}$. In experimentally infected mice, histopathological smear analysis revealed that the chosen tissues for detecting T. gondii are the liver and spleen in the virulent strain $(\mathrm{RH})$, and the brain and kidney in the avirulent strain $\left(\right.$ ME49) ${ }^{[8]}$. 
Traditional chemicals or natural compounds that have limited access to the CNS and are of high toxicity to the host, are used in current therapeutic regimens. To treat these infections and allow the medication to cross the blood-brain barrier, improvements in drug administration and formulation are needed ${ }^{[9]}$. Toxoplasmosis is treated with a mixture of pyrimethamine and sulfadiazine that despite their sufficient efficacy, can have common toxic side effects such as allergy, bone marrow suppression, folic acid deficiency, and hematologic toxicity ${ }^{[10]}$. Spiramycin is a bacteriostatic macrolide that has long been demonstrated to be effective against toxoplasmosis in mice ${ }^{[11]}$. Anti-toxoplasmic activity of Spiramycin was tested in murine infection models using T. gondii virulent (RH) and avirulent (ME 49) strains. Treatment with a dose of 100 or $200 \mathrm{mg} / \mathrm{kg} /$ day showed minor side effects ${ }^{[12]}$. Several factors, including membrane permeability and solubility, influence the bioavailability of any drug, including Spiramycin ${ }^{[13]}$. Studies were promoted to improve the solubility and dissolution rate of drugs with low water solubility ${ }^{[14]}$.

Nanotechnology is the study of small materials with diameters ranging from a few nanometers to hundreds of nanometers. By affecting many biomolecules on the cell surfaces and intracellularly, this size can alter several physicochemical and biochemical properties of the cells. Accordingly, the use of nanotechnology in the treatment, tracking, prevention, and control of biological diseases is known as nanomedicine ${ }^{[15]}$. Nanomedicine applications use a variety of nanomaterials, including metals, lipids, and polymers, which are made up of various materials ${ }^{[16]}$. Because of their small size, NPs can pass through membrane barriers, resulting in increased reactivity ${ }^{[17]}$. Metal NPs with anti-parasitic properties, such as silver and gold, are of particular interest for this reason ${ }^{[18]}$. Therefore, this study aims to assess the therapeutic effect of AuNPs on experimentally infected mice with chronic toxoplasmosis.

\section{MATERIAL AND METHODS}

This experimental study was conducted from September to November 2019, at the National Research Centre, Cairo, Egypt.

Study design: The study included five groups; two control groups (non-infected non-treated, and infected non-treated), and three infected treated groups. Fifty days pi, mice were orally treated with Spiramycin, lowdose and high-dose AuNPs for 10 days. Sixty days pi, all mice were sacrificed and the therapeutic effect of AuNPs was assessed using parasitological, histopathological, and biochemical parameters.

Animals and T. gondii strain: Sixty-five laboratorybred female Swiss Albino mice, 6-8 weeks old; 20-25 $\mathrm{g}$ in weight, were purchased from the animal house,
National Research Centre, Cairo, Egypt. Mice were housed in well ventilated cages and were fed standard pellet food with free access to water. The ME49 strain was obtained from the batch maintained at the Zoonotic Diseases Department, National Research Center, Cairo, Egypt. Sixty mice were experimentally infected orally with 20 cysts/mouse. Five mice served as control negative group and their serum samples were used for determination of the liver enzymes levels.

Gold NPs preparation: AuNPs was purchased from NanoTech Egypt company for Photo-Electonics, Cairo, Egypt and was prepared by chemical reduction method $^{[19]}$. Briefly, HAuCl4 solution was used as Au3+ ions precursor; while sodium citrate was used as mild reducing and stabilizing agent. Using transmission electron microscopy, properties of AuNPs were determined as sperical, water soluble particles of $15 \pm 5 \mathrm{~nm}$, with average size $(\lambda \max =520 \pm 3 \mathrm{~nm})$, and $196 \mathrm{ppm}$ concentration in its liquid form (Figure 1).

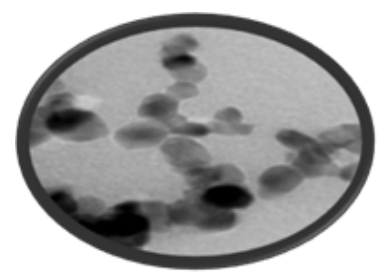

Fig. 1. AuNPs properties by transmission electron microscopy (TEM).

Animal grouping: Fifty days pi, infected mice were randomly divided into 4 equal groups (15 mice each). Group 1 included non-treated control positive mice. Groups 2, 3 and 4 were treated orally by esophageal tube for 10 days with Spiramycin $(100 \mathrm{mg} / \mathrm{kg} /$ day $)$, low dose $(400 \mu \mathrm{g} / \mathrm{kg} /$ day) and high dose ( $800 \mu \mathrm{g} / \mathrm{kg} /$ day $)$ of AuNPs, respectively.

Impression smears: Estimation of $T$. gondii cysts count and size in impression smears ${ }^{[20]}$ stained with Giemsa was performed from brain, liver and spleen of all infected mice. Three smears of each organ/mouse were examined using oil immersion and the mean of 10 different fields was calculated ${ }^{[21-22]}$.

Histopathological assessment: Sections from brain, liver and spleen of G 1-4 infected with $T$. gondii were examined after staining with Haematoxylin and Eosin $(\mathrm{HE})^{[23]}$

Biochemical assessment: After sacrifice of all mice including negative control group, one ml blood sample was obtained from each mouse to measure liver transaminases; AST and ALT levels. Enzymes were colorimetrically determined in sera of the all groups using spectrophotometery (Janway, Keison Products, $(\mathrm{UK})^{[24]}$. The kits were obtained from Spectrum, Cairo, Egypt). 
Statistical analysis: Data were organized, tabulated, and statistically analyzed using SPSS version, 16.00. For quantitative data, mean, percentage and standard deviation were calculated. ANOVA test was used to compare variables between groups. Results were considered significant when $P$ value was $<0.05$.

Ethical statement: The present study was approved from Research and Ethic committee of the Faculty of Medicine, Sohag University, Egypt. Animal experiments complied with the Egyptian national regulations according to the procedures for using laboratory animals and in accordance with the internationally accepted principles for laboratory animal use and care.

\section{RESULTS}

Estimation of cysts count and size in impression smears in the brain, liver, and spleen: There was significant reduction in the mean number (Table 1) and size (Table 2) of cysts in the brain, liver and spleen of
G4 compared to other three groups $(P<0.001)$. Using Post Hoc test, there was a statistically significant reduction in the mean cyst count and size in brain, liver and spleen of infected treated groups with high dose AuNPs compared to the infected non-treated control and infected mice treated with Spiramycin. In addition, it showed a statistically significant reduction in the mean cyst count and a statistically non-significant reduction in the mean cyst size in brain, liver and spleen of infected treated group with high dose AUNPs compared to infected treated group with low dose AuNPs (Table 3).

Figure (2) presents the effect of treatment on the size of the cysts in G2 (reduction in size), G3 and G4 (degenetated cysts) in comparison to normal cyst size in G1. T. gondii cysts were larger in size and more frequently detected in non-treated mice G1 (A and B) compared to Spiramycin treated mice G2 (C). Few degenerated cysts were detected in low dose AuNPs treated mice G3 (D) and high dose AuNPs treated mice G4 (E).

Table 1. Comparisons between cysts count in brain, liver, and spleen of the study groups.

\begin{tabular}{|c|c|c|c|c|}
\hline \multirow{2}{*}{ Organ } & \multirow{2}{*}{ Groups } & \multirow{2}{*}{ Mean count \pm SD $(\mathrm{SE})$} & \multicolumn{2}{|c|}{ Statistical analysis } \\
\hline & & & 95\% confidence interval ${ }^{@}$ & $P$ value \\
\hline Brain & $\begin{array}{l}\text { Control } \\
\text { Spiramycin } \\
\text { AuNPs (low) } \\
\text { AuNPs (high) } \\
\text { Total }\end{array}$ & $\begin{array}{c}18.93 \pm 1.10(0.63) \\
8.20 \pm 0.52(0.30) \\
3.00 \pm 0.34(0.20) \\
0.13 \pm 0.11(0.06) \\
7.56 \pm 7.50(2.16)\end{array}$ & $\begin{array}{c}16.19-21.67 \\
6.88-9.51 \\
2.13-3.86 \\
0.15-0.42 \\
2.79-12.34 \\
\end{array}$ & 0.000 \\
\hline Liver & $\begin{array}{l}\text { Control } \\
\text { Spiramycin } \\
\text { AuNPs (low) } \\
\text { AuNPs (high) } \\
\text { Total }\end{array}$ & $\begin{array}{c}20.46 \pm 1.70(0.98) \\
7.86 \pm 0.30(0.17) \\
3.20 \pm 0.20(0.11) \\
0.26 \pm 0.11(0.06) \\
7.95 \pm 8.09(2.33)\end{array}$ & $\begin{array}{c}16.24-24.69 \\
7.10-8.62 \\
2.70-3.69 \\
0.02-0.55 \\
2.80-13.1 \\
\end{array}$ & 0.000 \\
\hline Spleen & $\begin{array}{l}\text { Control } \\
\text { Spiramycin } \\
\text { AuNPs (low) } \\
\text { AuNPs (high) } \\
\text { Total }\end{array}$ & $\begin{array}{c}19.80 \pm 1.40(0.8) \\
8.06 \pm 0.60(0.8) \\
3.33 \pm 0.11(0.06) \\
0.20 \pm 0.20(0.11) \\
7.85 \pm 7.80(2.25)\end{array}$ & $\begin{array}{c}16.32-23.27 \\
6.46-9.66 \\
3.04-3.62 \\
0.29-0.69 \\
2.89-12.80 \\
\end{array}$ & 0.000 \\
\hline
\end{tabular}

SD: Standard deviation; SE: Standard error; @: Lower and upper 95\% confidence interval for means, \#: $P$ value within the groups (Significant <0.05)

Table 2. Comparisons between cysts size $(u)$ in the brain, liver, and spleen of study groups.

\begin{tabular}{|c|c|c|c|c|}
\hline \multirow{2}{*}{ Organ } & \multirow{2}{*}{ Groups } & \multirow{2}{*}{ Mean size \pm SD (SE) } & \multicolumn{2}{|c|}{ Statistical analysis } \\
\hline & & & 95\% confidence interval ${ }^{@}$ & $P$ value $^{\#}$ \\
\hline Brain & $\begin{array}{l}\text { Control } \\
\text { Spiramycin } \\
\text { AuNPs (low) } \\
\text { AuNPs (high) } \\
\text { Total } \\
\end{array}$ & $\begin{array}{c}55.00 \pm 5.00(2,88) \\
25.00 \pm 5.00(2.88) \\
4.33 \pm 1.15(0.6) \\
1.66 \pm 1.52(0.8) \\
21.50 \pm 22.51(6.49)\end{array}$ & $\begin{array}{c}42.57-67.42 \\
12.57-37.42 \\
1.46-7.20 \\
2.12-5.46 \\
7.19-35.80 \\
\end{array}$ & 0.000 \\
\hline Liver & $\begin{array}{l}\text { Control } \\
\text { Spiramycin } \\
\text { AuNPs (low) } \\
\text { AuNPs (high) } \\
\text { Total } \\
\end{array}$ & $\begin{array}{c}65.00 \pm 5.00(2.88) \\
30.00 \pm 5.0(2.88) \\
5.33 \pm 0.57(0.33) \\
3.66 \pm 1.15(0.66) \\
26.00 \pm 26.0(7.53)\end{array}$ & $\begin{array}{c}52.57-77.42 \\
17.57-42.42 \\
3.89-6.76 \\
79.82-6.53 \\
9.41-42.58 \\
\end{array}$ & 0.000 \\
\hline Spleen & $\begin{array}{l}\text { Control } \\
\text { Spiramycin } \\
\text { AuNPs (low) } \\
\text { AuNPs (high) } \\
\text { Total }\end{array}$ & $\begin{aligned} 63.33 & \pm 7.63(4.40) \\
25.00 & \pm 5.00(2.88) \\
4.66 & \pm 1.52(0.8) \\
1.33 & \pm 1.15(0.6) \\
23.58 & \pm 26.07(7.52)\end{aligned}$ & $\begin{array}{c}44.36-82.30 \\
12.57-37.42 \\
0.80-8.46 \\
1.53-4.20 \\
7.01-40.15\end{array}$ & 0.000 \\
\hline
\end{tabular}


Table 3. Comparisons between cysts count and size (in microns) in the brain, liver, and spleen of mice G4 (high dose AUNPs) and the other study groups using Post Hoc test.

\begin{tabular}{|c|c|c|c|c|}
\hline \multirow{2}{*}{ Organ } & \multirow{2}{*}{ Groups } & \multirow{2}{*}{ Mean difference \pm SD $(\mathrm{SE})$} & \multicolumn{2}{|c|}{ Statistical analysis } \\
\hline & & & 95\% confidence interval ${ }^{@}$ & $P$ value ${ }^{\#}$ \\
\hline Brain & Control vs AuNPs (high) & $18.80 \pm 0.99(0.52)$ & $17.30-20.29$ & 0.000 \\
\hline cyst & Spiramycin vs AuNPs (high) & $8.06 \pm 0.41(0.52)$ & $6.56-9.56$ & 0.000 \\
\hline count & AuNPs (low) vs AuNPs (high) & $2.86 \pm 0.23(0.52)$ & $1.36-4.36$ & 0.001 \\
\hline Liver & Control vs AuNPs (high) & $20.20 \pm 1.59(0.71)$ & $18.15-22.25$ & 0.000 \\
\hline cyst & Spiramycin vs AuNPs (high) & $7.60 \pm 0.19(0.71)$ & $5.55-9.65$ & 0.000 \\
\hline count & AuNPs (low) vs AuNPs (high) & $2.93 \pm 0.09(0.71)$ & $0.88-4.98$ & 0.009 \\
\hline Spleen & Control vs AuNPs (high) & $19.60 \pm 1.2(0.63)$ & $17.76-21.43$ & 0.000 \\
\hline cyst & Spiramycin vs AuNPs (high) & $7.86 \pm 0.4(0.63)$ & $6.03-9.69$ & 0.000 \\
\hline count & AuNPs (low) vs AuNPs (high) & $3.13 \pm 0.09(0.63)$ & $1.30-4.96$ & 0.003 \\
\hline Brain & Control vs AuNPs (high) & $53.33 \pm 3.48(2.99)$ & $44.72-61.94$ & 0.000 \\
\hline cyst & Spiramycin vs AuNPs (high) & $23.33 \pm 3.48(2.99)$ & $14.72-31.94$ & 0.000 \\
\hline size & AuNPs (low) vs AuNPs (high) & $2.66 \pm 0.37(2.99)$ & $5.94-11.27$ & 0.71 \\
\hline Liver & Control vs AuNPs (high) & $61.33 \pm 3.85(2.93)$ & $52.88-69.78$ & 0.000 \\
\hline cyst & Spiramycin vs AuNPs (high) & $26.33 \pm 3.85(2.93)$ & $17.88-34.78$ & 0.000 \\
\hline size & AuNPs (low) vs AuNPs (high) & $1.66 \pm 4.62(2.93)$ & $6.78-10.11$ & 0.894 \\
\hline Spleen & Control vs AuNPs (high) & $62.00 \pm 6.46(3.80)$ & $51.03-72.96$ & 0.000 \\
\hline cyst & Spiramycin vs AuNPs (high) & $23.66 \pm 3.85(3.80)$ & $12.70-34.63$ & 0.000 \\
\hline size & AuNPs (low) vs AuNPs (high) & $3.33 \pm 0.37(3.80)$ & $7.63-14.29$ & 0.722 \\
\hline
\end{tabular}

SD: Standard deviation; SE: Standard error; @: Lower and upper 95\% confidence interval for means, \#: P value within the groups (Significant <0.05).
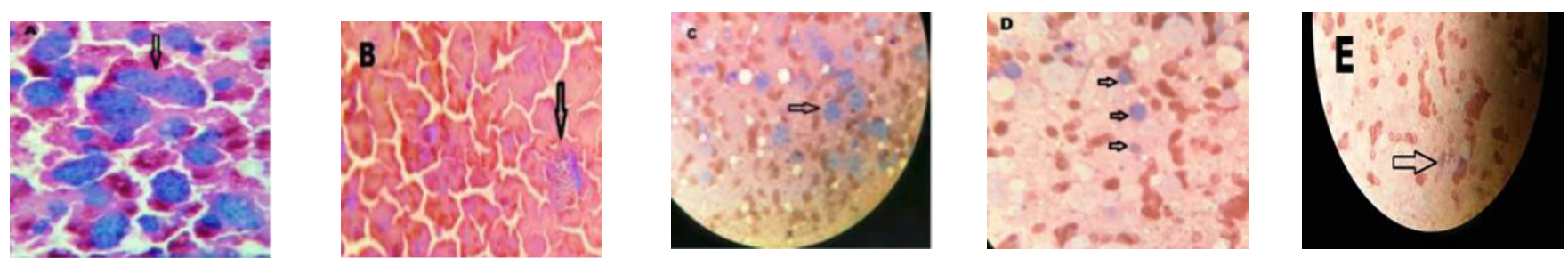

Fig. 2. Impression smears of liver tissue of $T$. gondii infected mice stained by Geimsa stain. T. gondii cysts (arrows) were detected more frequently and were larger in size in non-treated G1 mice (A and B) compared to Spiramycin-treated G2 mice (C). Few degenerated cysts were detected in low dose AUNPs-treated G3 mice (D), and high dose AuNPs treated G4 mice (E). (X100).

\section{Histopathological study results}

Brain (Fig. 3): In general, the brain tissue showed normal appearance with no necrosis or hemorrhage. The histological changes in mice of different groups were mild displaying $T$. gondii cysts surrounded by increased cellularity of adjacent glial tissue and increased inflammatory cells mainly macrophages and neutrophils. The number of cysts were reduced in G2 (Fig. 3B) and G3 (Fig. 3C) relative to G1 (Fig. 3A). The cysts were rare and degenerated in G4 (Fig. 3D). Size of cysts were smaller in treated mice. The cellularity of glial tissue and infiltration by macrophages were less frequent in G3 and G4 compared to G2 and G1.

Liver (Fig. 4): The liver tissue architecture, hepatic lobules and portal tracts were almost preserved in mice of different groups. The main histological findings recorded minimal foci of necrosis in G1 (Fig. 4A). Hepatocyte degenerative changes (cloudy swelling and micro-vesicular steatosis) were observed in G1 (Fig. 4A) and G2 (Fig. 4B), occasionally in G3 (Fig. 4C) and less frequently in G4 (Fig. 4D). Infiltration by lymphocytes, neutrophils and less frequently histiocytes was observed in portal tracts and hepatic lobules (portal and lobular inflammation). The inflammatory reaction was diffuse and moderate-to- strong in G1 (Fig. 4A), mild to moderate in G2 (Fig. 4B) and minimal-to-mild in G3 (Fig. 4C) and G4 (Fig. 4D). T. gondii cysts were observed in G1 (Fig. 4A), and less frequently seen in G2 (Fig. 4B). Few or rare were found in G3 (Fig. 4C) and they are almost absent in G4 (Fig. 4D).

Spleen (Fig. 5): In general, the splenic red and white pulps were preserved and the splenic capsule was intact. No sub-capsular hemorrhage or necrosis were observed. The main histological changes included dilated lymphoid sinuses (red pulp) and focal reactive hyperplasia of the lymphoid follicles in mice of different groups. Splenic sinuses were infiltrated by inflammatory cells mainly macrophages, lymphocytes, and giant cells. The inflammatory reaction was diffuse and heavy in G1 (Fig. 5A) and G2 (Fig. 5B) and still diffuse but mild to moderate in G3 (Fig. 5C) and G4 (Fig. 5D). T. gondii cysts were observed mainly in G1 (Fig. 5A) and G2 (Fig. 5B). They were less frequent in number in G3 (Fig. 5C) and G4 (Fig. 5D).

Biochemical results: Mean values of ALT and AST as measured in non-infected mice were 15.02 and 51.03, respectively and corresponded to levels recorded in G4. The AST level was raised in the other groups being highest (61.67) in G1 (Table 4). 

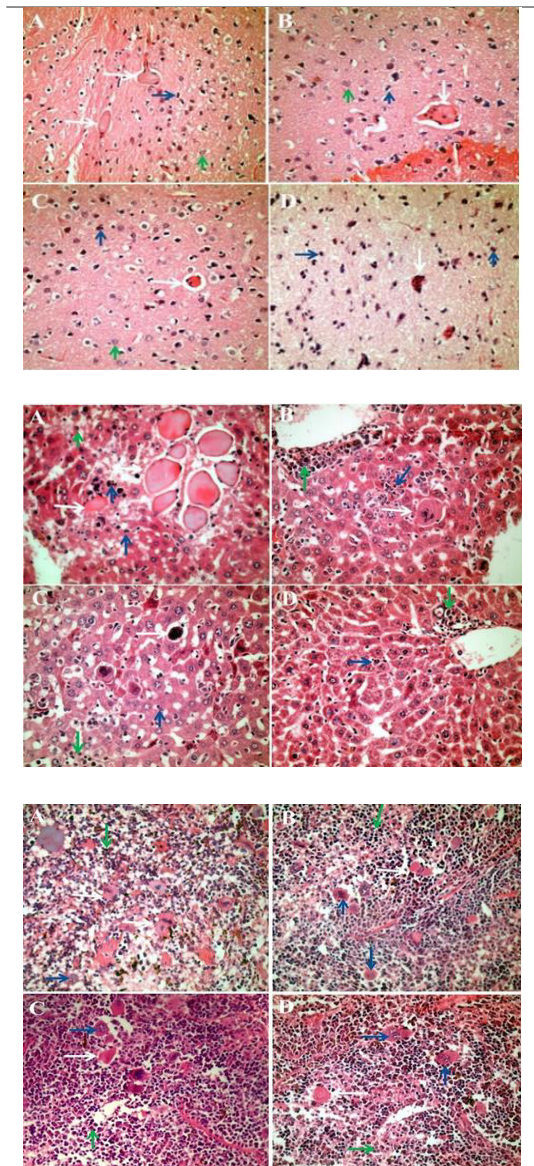

Fig. 3. Histological sections of brain tissue of T. gondii infected mice. Cysts (white arrows) were detected more frequently in non-treated G1 mice (A) compared to Spiramycin treated G2 mice (B). Few degenerated cysts were detected in G3-low dose AuNPs and G4-high dose AuNPs treated mice (C and D, respectively). Infiltration by neutrophils (blue arrows) and macrophages (green arrows) and cellularity of glial tissue were slightly reduced in treated mice compared to control G1. H\&E stained sections (X400).

Fig. 4. Histological sections of liver tissue of T. gondii infected mice. Large sized cysts were detected in non-treated G1 mice (A). The cysts were smaller in size in Spiramycin treated G2 mice (B). Few degenerated cysts were detected in low dose AuNPs treated G3 mice (C) and they were almost absent in high dose AuNPs treated G4 mice (D). Portal and lobular infiltration by lymphocytes (green arrows) and neutrophils (blue arrows) was high in G1 and G2, and the inflammatory infiltrate was mild in G3 and minimal in G4. H\&E stained sections; (X400).

Fig. 5. Histological sections of splenic tissue of T. gondii infected mice. There was diffuse infiltration of splenic sinuses by inflammatory cell reaction mainly lymphocytes (green arrows) and giant cells (blue arrows) in different groups. Cysts (black arrows) were detected in non-treated G1 mice (A) and Spiramycin treated G2 mice (B). They were less frequently detected in low dose AuNPs treated G3 mice (C) and high dose AuNPs treated G3 mice (D). H\&E stained sections (X400).

Table 4. Comparison between liver transaminases ALT and AST in all groups of mice.

\begin{tabular}{lllc}
\hline \hline $\begin{array}{c}\text { Liver } \\
\text { enzymes }\end{array}$ & \multicolumn{1}{c}{ Groups } & Mean \pm SD (SE) & \multicolumn{1}{c}{ Statistical analysis } \\
\cline { 3 - 4 } & & & 95\% confidence interval $^{@}$ \\
\multirow{4}{*}{ ALT } & Control negative & $15.02 \pm 1.58(1.12)$ & $14.25-15.35$ \\
& Control positive & $18.80 \pm 2.44(0.81)$ & $16.23-19.98$ \\
& Spiramycin & $18.64 \pm 2.10(0.94)$ & $16.03-21.27$ \\
& AuNPs (low) & $15.44 \pm 0.41(0.18)$ & $14.73-15.76$ \\
& AuNPs (high) & $15.27 \pm 0.85(0.38)$ & $14.42-15.54$ \\
\multirow{4}{*}{ AST } & Control negative & $51.02 \pm 4.41(3.11)$ & $38.42-63.88$ \\
& Control positive & $61.67 \pm 5.15(1.71)$ & $53.06-60.99$ \\
& Spiramycin & $57.25 \pm 4.45(1.99)$ & $51.64-62.70$ \\
& AuNPs (low) & $57.17 \pm 2.30(1.03)$ & $54.38-60.12$ \\
\hline \hline
\end{tabular}

SD: Standard deviation; SE: Standard error; @: Lower and upper 95\% confidence interval for means, \#: $P$ value within the groups (Significant <0.05).

\section{DISCUSSION}

Drugs used at the present time against toxoplasmosis neither achieve complete killing of bradyzoites nor clearance of all cysts, leading to the risk of reactivation in immunocompromised patients ${ }^{[25]}$. Simultaneously treatment of chronic toxoplasmosis is often difficult due to the poor reach of drugs to brain ${ }^{[26]}$. Moreover, prolonged use of these drugs may cause hematologic and renal toxicities ${ }^{[27]}$. Increased side effects and insufficient efficiencies of these drugs, especially against chronic toxoplasmosis, require further research for safe and effective therapeutic agents ${ }^{[28]}$. In the present study, a statistically significant reduction $(P=0.000)$ occurred in the mean cyst count and size in brain, liver and spleen of infected treated group with high dose AuNPs compared to the other groups. Similar significant decrease was noticed in mice treated by silver NPs alone or combined with chitosan NPs ${ }^{[29]}$.

A study by Azami et al. ${ }^{[30]}$ showed the potential of curcumin nano-emulsion (CR-NE) in the treatment of acute and chronic experimental toxoplasmosis. In acute stage, the survival time of mice infected with $\mathrm{RH}$ strain and treated with CR-NE extended from 8 to 10 days post- treatment. The differences were statistically significant $(P<0.001)$ between the survival time of mice in CR-NE-treated group compared with negative control group. Additionally, CR-NE significantly decreased the mean counts of peritoneum tachyzoites in CRNE-treated mice compared to negative control group $(P<0.001)$. In a chronic stage experiment, the average 
number and size of tissue cysts significantly decreased in mice inoculated with bradyzoites of Tehran strain and treated with CR-NE compared with that in negative control group $(P<0.001)$. More recent, El-Shafey et al. ${ }^{[8]}$ showed that curcumin and curcumin incorporated in metal organic frameworks nanocomposite significantly decreased the mean count of cysts in brains of the treated rats infected with ME49 strain.

Histopathological examination of the brain, liver, and spleen tissues in the present work showed that the inflammatory reaction was diffuse and moderate to strong in control non treated mice, mild to moderate in Spiramycin treated mice and minimal to mild in infected treated group with low dose AuNPS and infected treated group with high dose AuNPS. These results are substantiated by previous statements ${ }^{[31,32]}$. Furthermore, as in previous reports, large sized Toxoplasma cysts were detected in organs of nontreated mice ${ }^{[33,34]}$. The cysts were smaller in size in Spiramycin treated mice. Few degenerated cysts were detected in the infected treated group with low dose AuNPS, and were almost absent in infected treated group with high dose AuNPS which agreed with the results of light microscopic examination of impression smears of the same organs and groups.

For further assessment of the effect of AuNPS on T. gondii cysts in our study, biochemical evaluation of liver enzymes levels was done. Rise of ALT and AST levels was reported as the first sign of hepatic injury induced by toxoplasmosis ${ }^{[35]}$. The reverse of that elevation by NPs is a clear indication of enhancement of the functional status of hepatocytes showing the hepato-protective activity of NPs ${ }^{[36]}$. Our results found that while ALT levels were apparently slightly but significantly reduced in low and high AuNPs treated groups compared to control positive and Spiramycin treated groups, the AST levels were significantly $(P<0.05)$ reduced in low and high AuNPs and Spiramycin treated groups compared to control positive group. This reduction in liver enzymes reflects the safety of AuNPs and Spiramycin administration. This was confirmed by Alajmi et al. ${ }^{[37]}$ who proved the anti-Toxoplasma activity of silver NPs synthesized with Phoenix dactylifera and Ziziphus spina-christi extracts. Inhibition of inflammation in livers of Balb/c mice was achieved by regulation of cytokines. EL-Zawawy et $a l^{[38]}$ found significantly elevated but reversible liver transaminases (AST and ALT) in cystogenic ME49 infected and triclosan liposomal NPs treated subgroups. This was attributed to the hepatitis caused by high triclosan dose. The authors concluded that the level of AST and ALT in triclosan liposomal nanoparticles treated subgroup was statistically significantly decreased compared to triclosan treated subgroup. This was explained by liposomal encapsulation of triclosan which could ameliorate the effect of triclosan alone on liver cells. According to Pissuwan et al. ${ }^{[39]}$, the death rate of tachyzoites in vitro was elevated by dose- dependent levels of AuNPs in a given laser dose, but there was no significant change in the death rate when the laser dose was elevated on a fixed concentration of AuNPs.

At the end of this study, we can conclude that AuNPS have a potent therapeutic effect especially the high dose $(800 \mu \mathrm{g} / \mathrm{kg} /$ day $)$ against experimental chronic toxoplasmosis (avirulent ME49 strain). AuNPS induced a significant diminution in the parasite burden. This was supported by the histopathological distortive effect of the drug on the cysts as proved by the histopathological study. AuNPS caused significant reduction of the liver transaminases (ALT and AST).

Author contribution: GabAllah MR designed the study, shared Barakat AMA and Ahmed NS in performing the experiments and wrote the manuscript. El-Nadi NA shared in research planning and writing the manuscript. All authors critically revised the manuscript.

Conflict of interest: Authors confirm that there are no known conflicts of interest associated with this study.

Funding statement: This research did not receive any specific grant from funding agencies in the public, commercial, or not-for-profit sectors.

\section{REFERENCES}

1. Weiss LM, Dubey JP. Toxoplasmosis: A history of clinical observations. Int J Parasitol 2009; 39(8):895-901.

2. Robert-Gangneux F, Dardé ML. Epidemiology of and diagnostic strategies for toxoplasmosis. Clin MicrobiolRev 2012; 25(3):264-296.

3. Jongert E, Roberts CW, Gargano N, Forster-Waldl E, Petersen E. Vaccines against Toxoplasma gondii: challenges and opportunities. Mem Inst Oswaldo Cruz 2009; 104: 252-266

4. Montoya JG, Liesenfeld 0. Toxoplasmosis. Lancet 2004; 363:1965-1976.

5. Weiss LM, Kim K. The development and biology of bradyzoites of Toxoplasma gondii. Front Biosci 2000; 5:391-405.

6. Remington JS, McLeod R, Thulliez P, Desmonts G. Toxoplasmosis: Infectious disease of the fetus and newborn, $5^{\text {th }}$ ed; Elsevier Saunders. Philadelphia; 2001, 205-346.

7. Montoya G. Laboratory diagnosis of Toxoplasma gondii infection and toxoplasmosis. J Inf Dis 2002; 185(Suppl 1): 73-82.

8. El-Shafey AAM, Hegab MHA, Seliem MME, Barakat AMA, Mostafa NE, Abdel-Maksoud HA, et al. Curcumin ${ }^{\circledR}$ metal organic frameworks nano-composite for treatment of chronic toxoplasmosis. J Mater Sci Mater Med 2020; 31(11):90.

9. Gondim B, da Silva Catarino J, de Sousa M, de Oliveira Silva M, Lemes M R, de Carvalho-Costa TM, et al. Nanoparticlemediated drug delivery: blood-brain barrier as the main obstacle to treating infectious diseases in CNS. Curr Pharm Des 2019; 25(37):3983-3996. 
10. Martins-Duarte ES, Urbina JA, de Souza W, Vommaro RC. Antiproliferative activities of two novel quinuclidine inhibitors against Toxoplasma gondii tachyzoites in vitro. J Antimicrob Chemother 2006; 58(1):59-65.

11. Engel A, Biological applications of scanning probe microscopes. Annu Rev Biophys Biophys Chem 1991; 20: 79-108.

12. Grujiè J, Djurkovi-Djakovi O, Nikolic A, Klun I, Bobic B. Effectiveness of spiramycin in murine models of acute and chronic toxoplasmosis. Int J Antimicrob Agents 2005; 25(3):226-230.

13. Mourier P, Brun A. Study of the metabolism of spiramycin in pig liver. J Chromatogr B Biomed Sci Appl 1997; 704:197205.

14. Paradkar A, Ambike A, Jadhav B, Mahadik K. Characterization of curcumin-PVP solid dispersion obtained by spray drying. Int J Pharm 2004; 271:281-286.

15. Salata 0. Applications of nanoparticles in biology and medicine. J Nanobiotechnology 2004; 2(1):3.

16. Gutiérrez V, Seabra AB, Reguera RM, Khandare J, Calderón M. New approaches from nanomedicine for treating leishmaniasis. Chem Soc Rev 2016; 45(1):152-168.

17. Adeyemi OS, Faniyan TO. Antioxidant status of rats administered silver nanoparticles orally.J Taibah University Med Sci 2014; 9:182-186.

18. El-Khadragy M, Alolayan EM, Metwally DM, El-Din MFS, Alobud SS, Alsultan NI et al. Clinical efficacy associated with enhanced antioxidant enzyme activities of silver nanoparticles biosynthesized using Moringa oleifera leaf extract, against cutaneous leishmaniasis in a murine model of Leishmania major. Int J Environ Res Public Health 2018; 15:1037-1043.

19. Turkevich J, Stevenson PC, Hillier J. A study of the nucleation and growth processes in the synthesis of colloidal gold. Faraday Soc 1951; 11:55-75.

20. Manamperi NH, Chandu de Silva MV, Pathirana N, Abeyewickreme W, Karunaweera ND. Tissue impression smears as a supplementary diagnostic method for hstopathology in cutaneous leishmaniasis in Sri Lanka. Am J Trop Med Hyg 2018; 98(3):759-762.

21. Thiptara A, Kongkaew W, Bilmad U, Bhumibhamon T, Anan S. Toxoplasmosis in piglets. Ann NY Acad Sci 2006; 1081:336-338.

22. Barakat AMA. Some diagnostic studies on male New Zealand rabbit experimentally infected with Toxoplasma gondii strain. Glob Vet 2007; 1(1):17-23.

23. Bilqees FM, Fatima H. Microtomy and histopathology techniques. MAH Qadri Biological Research Centre, University of Karachi. 1993; 1-16.

24. Paul KB, Hedge JM, DeVito MJ, Crofton KM. Short-term exposure to triclosan decreases thyroxine in vivo via upregulation of hepatic catabolism in young long-evans rats. Toxicol Sci 2010; 113(2):367-379.

25. Lai BS, Witola WH, El Bissati K, Zhou Y, Mui E, Fomovska A, et al. Molecular target validation, antimicrobial delivery, and potential treatment of Toxoplasma gondii infections. Proc Natl Acad Sci USA 2012; 109(35):14182-14187

26. Faucher B, Moreau J, Zaegel O, Franck J, Piarroux R. Failure of conventional treatment with pyrimethamine and sulfadiazine for secondary prophylaxis of cerebral toxoplasmosis in a patient with AIDS. J Antimicrob Chemother 2011; 66(7):1654-1656.

27. Crespo M, Quereda C, Pascual J, Rivera M, Clemente L, Cano T. Patterns of sulfadiazine acute nephrotoxicity. Clin Nephrol 2000; 54(1):68-72.

28. Lahlou M. The success of natural products in drug discovery. Pharmacol Pharm 2013; 4(3):17-31.

29. Gaafar MR, Mady RF, Diab RG, Shalaby TI. Chitosan and silver nanoparticls: promising anti-Toxoplasma agents. Exp Parasitol 2014; 143:30-38.

30. Azami SJ, Teimouri A, Keshavarz H, Amani A, Esmaeili $\mathrm{F}$, Hasanpour $\mathrm{H}$ et al, Curcumin nanoemulsion as a novel chemical for the treatment of acute and chronic toxoplasmosis in mice. Int J Nanomedicine 2018; 13:7363-7374.

31. Chen J, Huang SY, Zhou DH, Li ZY, Petersen E, Song HQ, et al. DNA immunization with eukaryotic initiation factor-2a of Toxoplasma gondii induces protective immunity against acute and chronic toxoplasmosis in mice. Vaccine 2013; 31(52):6225-6231.

32. Mady RF, El-Hadidy W, Elachy, S. Effect of Nigella sativa oil on experimental toxoplasmosis. Parasitol Res 2016; 115:379-390.

33. Mcleod R, Frenkel JK, Estes RG, Mack DG, Eisenhauer $\mathrm{PB}$, Gibori G. Subcutaneous and intestinal vaccination with tachyzoites of Toxoplasma gondii and acquisition of immunity to per oral and congenital Toxoplasma challenge. J Immunol 1988; 140(5):1632-1637.

34. El-Temsahy MM, El Kerdany ED, Eissa MM, Shalaby TI, Talaat IM, Mogahed NM. The effect of chitosan nanospheres on the immunogenicity of Toxoplasma lysate vaccine in mice. J Parasit Dis 2016; 40(3):611-626.

35. Almeer RS, Alarifi S, Alkahtani S, Ibrahim SR, Ali D, Moneim A. The potential hepatoprotective effect of royal jelly against cadmium chloride-induced hepatotoxicity in mice is mediated by suppression of oxidative stress and upregulation of Nrf2 expression. Biomed Pharmacother 2018; 106:1490-1498.

36. He JJ, Ma J, Elsheikha HM, Song HQ, Zhou DH, Zhu XQ. Proteomic profiling of mouse liver following acute Toxoplasma gondii infection. PLoS One 2016; 11, e0152022.

37. Alajmi RA, Al-Megrin WA, Metwally D, Al-Subaie H, Altamrah N, Barakat AM et al. Anti-Toxoplasma activity of silver nanoparticles green synthesized with Phoenix dactylifera and Ziziphus spina-christi extracts which inhibits inflammation through liver regulation of cytokines in Balb/c mice. Biosci Rep 2019; 39(5): 20190379.

38. El-Zawawy LA, El-Said D, Mossallam SF, Ramadan HS, Younis SS. Preventive prospective of triclosan and triclosan-liposomal nanoparticles against experimental infection with a cystogenic ME49 strain of Toxoplasma gondii. Acta Trop 2015; (141):103-111.

39. Pissuwan D, Valenzuela SM, Miller CM, Cortie MB. A golden bullet? Selective targeting of Toxoplasma gondii tachyzoites using antibody-functionalized gold nanorods. Nano Lett 2007; 7(12), 3808-3812. 